\section{Intranasal glucagon in the treatment of hypoglycaemic attacks in children: experience at a summer camp}

Dear Sir,

We have recently shown $[1,2]$ that intranasal glucagon (i. n.-glucagon) was effective in quickly correcting experimentally-induced hypoglycaemia in volunteer diabetic patients. We observed that the i. n.-route initiated a blood glucose rise earlier than did the subcutaneous injection, although the effect of the latter was more sustained. We concluded that i.n.-glucagon was probably a clinically relevant alternative to its parenteral equivalent. We would like to report the results of a controlled study done on diabetic children at a summer camp. Informed consent was obtained from the parents of the children who participated in this study: they accepted that if a severe hypoglycaemic episode occurred it would be treated by glucagon, administered either intranasally or subcutaneously, on a random basis. Twenty consecutive severe hypoglycaemic events (i. e. hypoglycaemic status in which oral glucose administration was judged as impractical or potentially hazardous by the leader of the group, always a medical doctor) occurred spontaneously during leisure activities in 20 young diabetic subjects. As soon as the decision was taken to administer glucagon, a capillary blood glucose determination was done using a glucometer (Glucometer II, Ames-Bayer Diagnostics, Puteaux, France) and Glucostix strips. A box was then opened which randomly contained either a $1 \mathrm{mg}$ glucagon kit for s.c.

Table 1. Comparative effects of intranasal and subcutaneous glucagon in 20 hypoglycaemic children (mean \pm SEM)

\begin{tabular}{lcc}
\hline & Intranasal & Subcutaneous \\
\hline$n$ & $13^{\mathrm{a}}$ & $7^{\mathrm{a}}$ \\
Age (years) & $13 \pm 1$ & $13 \pm 1$ \\
Sex (male/female) & $6 / 7$ & $5 / 2$ \\
Blood glucose at $\mathrm{t}_{0}(\mathrm{mmol} / \mathrm{l})$ & $2.4 \pm 0.3$ & $3.2 \pm 0.3$ \\
Blood glucose increment & & \\
(mmol/l) & $2.9 \pm 0.8(13)$ & $2.2 \pm 0.6(6)$ \\
$\quad \mathrm{t}_{10} \mathrm{t}_{0}$ & $3.1 \pm 1.0(11)$ & $6.1 \pm 2.0(5)$ \\
$\mathrm{t}_{30} \mathrm{t}_{0}$ & $3 \pm 1$ & $7 \pm 2$ \\
Operating time (min) & $18 \pm 3$ & $31 \pm 5$ \\
Clinical recovery $(\mathrm{min})$ & 4 & 3 \\
Side effects & 1 & 1 \\
Treatment failure & &
\end{tabular}

a unless otherwise indicated (number in parentheses)

Due to the ambulatory conditions of this trial, some blood glucose values are missing: in the intranasal groups, two values at $t_{30}$ and, in the s.c. group, one value at $t_{10}$ and two values at $t_{30}$. None of the mean values observed in the two groups was significantly different administration (Novo-Nordisk, Boulogne, France) or an i. n.-glucagon kit (the product to be insufflated into the nostril was made of a lyophylised mixture of $1 \mathrm{mg}$ glucagon $+1 \mathrm{mg}$ sodium glycocholate (Laboratoires Organn St. Denis, France), as previously described [2]. Blood glucose values were measured at recognition of the hypoglycaemic state $\left(t_{0}\right)$, then at $t_{+10 \mathrm{~min}}$ and $t_{+30 \mathrm{~min}}$; the time which elapsed between the decision to inject and completion of the injection (operating time delay); the time which elapsed until the subject was able to consciously take a glass of orange juice in his hand and drink it (clinical recovery). The results are shown in Table 1 . The main observations which could be drawn from this experience are: (1) that i.n.glucagon was quickly effective. We observed only one treatment failure with one dose of i. n.-glucagon in a child who, by mistake, had injected himself with twice the dosage of insulin when an i.v. injection of glucose had to be administered; we also observed one apparent failure with s.c.-glucagon in an epileptic boy whose blood glucose was $60 \mathrm{mg}$ at $\mathrm{t}_{0}$. (2) i.n.-glucagon was administered more rapidly than s.c.-glucagon, although the difference did not reach statistical significance. In any case all the users found the i.n.-route much easier to operate. (3) i.n.-glucagon seemed to act at least as rapidly as s.c.-glucagon. However, the increment over $30 \mathrm{~min}$ was two-fold greater with i.n.-glucagon although the difference was not significant. If this latter observation is confirmed by further studies involving a larger number of patients, this might be of interest in avoiding overcorrection of hypoglycaemia; this would be consistent with the pharmacological features of i.n. administered glucagon i.e. more rapid onset and shorter action [2,3]. (4) Side effects (headache, nausea, vomiting) were observed in both groups.

This work is the first to demonstrate and quantify the efficiency of i.n.-glucagon in the treatment of hypoglycaemic attacks under pragmatic conditions.

Yours sincerely,

G. Slama, G. Reach, M. Cahane, C. Quetin and F. Villanove-Robin

\section{References}

1. Freychet L, Rizkalla SW, Desplanque N et al. (1988) Effect of intranasal glucagon on blood glucose levels in healthy subjects and hypoglycaemic patients with insulin-dependent diabetes. Lancet II: $1364-1366$

2. Slama G, Alamowitch $C$, Desplanque N, Letanoux M, Zirinis $P$ (1990) A new non-invasive method for treating insulin-reaction: intranasal lyophylised glucagon. Diabetologia 33: 671-674

Dr. G. Slama

Service de Diabétologie

Hôtel-Dieu de Paris

1, place du Parvis Notre-Dame

F-75181 Paris Cedex 04

France 